\title{
New Synthesis route of Iron-Based Catalyst for Electrochemical Oxygen Reduction Reaction
}

\author{
Lu Qin ${ }^{1}$, Xiaochun $Y u^{1}$, Jun Li ${ }^{1,2, *}$, Shuangyan $\mathrm{Li}^{1}$, Yiyan Liu ${ }^{l}$, Pengcheng Qian ${ }^{1}$, \\ Jichang Wang ${ }^{2, *}$, Shun Wang ${ }^{1}$, Huile Jin ${ }^{1, *}$ \\ ${ }^{1}$ Nano-materials \& Chemistry Key Laboratory, Institute of New Materials and Industrial \\ Technologies, Wenzhou University, Wenzhou 325035, P. R. China. \\ ${ }^{2}$ Department of Chemistry and Biochemistry, University of Windsor, Windsor, ON, N9B 3P4, \\ Canada. \\ *E-mail: huilejin@wzu.edu.cn, junli@uwindsor.ca, jwang@uwindsor.ca
}

doi: $10.20964 / 2020.09 .26$

Received: 23 March 2020 / Accepted: 16 May 2020 / Published: 10 August 2020

\begin{abstract}
Among existed oxygen reduction electrocatalysts, iron-based catalysts have shown great advantages of low cost and extraordinary reactivity, which are even comparable to commercialized platinum based catalysts. However, the propensity of iron catalysts to aggregate and passivate has emerged as a fundamental barrier to high-power fuel cell applications. In this study, biomass egg yolk derived carbon nanotubes were designed as an armor to host iron complexes, offering multiple active sites such as $\mathrm{Fe}$ $\mathrm{N}_{\mathrm{x}}, \mathrm{Fe}_{3} \mathrm{C}, \mathrm{Fe}_{2} \mathrm{P}$ for efficient oxygen reduction reaction (ORR). Although the true active sites of ironbased catalysts on the enhanced ORR activities is still under debates, a consensus on the contributions of Fe- $\mathrm{N}_{\mathrm{x}}$ active center has been reached via a smart material design in this work, which enables ORR onset potential at $0.9 \mathrm{~V}$ vs. RHE with excellent four-electron selectivity in alkaline media. Meanwhile, the state-of-the-art carbon shells promote the performance stability remarkably (retaining above $96 \%$ of its activity after 27 hours).
\end{abstract}

Keywords: biomass derived, heteroatom doped carbon, supercapacitors, cycling stability, manganese dioxide

\section{FULL TEXT}

(C) 2020 The Authors. Published by ESG (www.electrochemsci.org). This article is an open access article distributed under the terms and conditions of the Creative Commons Attribution license (http://creativecommons.org/licenses/by/4.0/). 